\title{
Leukemia inhibitory factor and its receptor: expression and regulation in the porcine endometrium throughout the estrous cycle and pregnancy
}

\author{
Inkyu Yoo ${ }^{1, a}$, Soogil Chae, , Jisoo Han', Soohyung Lee', Hyun Jong Kim², and Hakhyun Ka"*
}

\begin{abstract}
* Corresponding Author: Hakhyun Ka Tel: +82-33-760-2369, Fax: +82-33-760-2183, E-mail: hka@yonsei.ac.kr
\end{abstract}

'Department of Biological Science and Technology, Yonsei University, Wonju 26493, Korea

2 Dairy Science Division, National Institute of Animal

Science, Rural Development Administration, Cheonan 31000 , Korea

a These authors contributed equally to this work.

ORCID

Hakhyun Ka

https://orcid.org/0000-0003-0213-5884

Submitted Jun 7, 2018; Revised Jul 23, 2018; Accepted Jul 26, 2018
Objective: Leukemia inhibitory factor (LIF) binds to a heterodimeric receptor composed of LIF receptor (LIFR) and glycoprotein 130 (GP130) to transmit signals into the cell. LIF plays an important role in reproduction by regulating immune response, decidualization, and implantation in several species. However, the expression of LIF and LIFR in the endometrium throughout the estrous cycle and pregnancy in pigs is not fully understood.

Methods: We analyzed the expression of LIF and LIFR in the endometrium on days 0 (estrus), $3,6,9,12,15$, and 18 of the estrous cycle, and days $12,15,30,60,90$, and 114 of pregnancy, in conceptuses on days 12 and 15, and in chorioallantoic tissues on days 30, 60, 90, and 114 of pregnancy in pigs. We also determined the effects of estrogen and progesterone on the expression of LIF and LIFR in endometrial tissues.

Results: The expression of $L I F$ increased in the endometrium during the late diestrus phase of the estrous cycle and during mid- to late- pregnancy, while the expression of LIFR increased during early pregnancy. The expression of $L I F$ was induced by increasing doses of estrogen, whereas the expression of LIFR was induced by increasing doses of progesterone. Conclusion: These results indicate that the expression of LIF and its receptor LIFR in the endometrium is regulated in a stage-specific manner during the estrous cycle and pregnancy, suggesting that LIF and its receptor signaling system may play critical roles in regulating endometrial function in pigs.

Keywords: Pig; Endometrium; Estrous Cycle; Pregnancy; Leukemia Inhibitory Factor; Leukemia Inhibitory Factor Receptor

\section{INTRODUCTION}

Leukemia inhibitory factor (LIF) is a pleiotropic member of the interleukin-6 (IL-6) family of cytokines [1,2]. LIF regulates cellular functions by binding to a membrane-bound heterodimeric receptor, LIF receptor (LIFR) and glycoprotein 130 (GP130) [3]. Binding of LIF to LIFR and GP130 forms a high affinity functional receptor complex and activates the Janus kinasesignal transducer and activator of the transcription signaling pathway [3,4]. In addition to the well-known function of LIF in inhibiting differentiation of mouse embryonic stem cells to maintain pluripotency and self-renewal [5], LIF is involved in a variety of biological processes such as cell differentiation, bone metabolism, inflammation, vascularization, and embryogenesis [3].

In the female reproductive tract, LIF plays important roles in regulation of immune response, decidualization, and implantation in several animal species $[1,3,6]$. In humans, LIF is expressed in the endometrial glands during the luteal phase of the menstrual cycle, and LIFR and GP130 are expressed in endometrial luminal epithelial cells during the cycle and 
in decidual stroma during early pregnancy $[7,8]$. LIF affects endometrial receptivity by inducing decidualization of stromal cells and increasing IL- 6 and IL-15 production in decidual cells during the implantation period [9]. In mice, Lif is expressed in endometrial glands at the highest levels on day 4 of pregnancy [10], while Lifr and Gp130 are expressed in luminal epithelial cells on days 3 to 5 of pregnancy [11]. Lif-null mice are infertile due to defects in implantation and decidualization $[2,12]$, and LIF induces recruitment of various leukocytes into the site of implantation in mice [1,6]. In pigs, the expression of $L I F$ and its receptor has been reported in the endometrium. $L I F$ is expressed in the endometrium between days 10 and 18 of the estrous cycle and early pregnancy $[13,14]$, and LIFR and GP130 are expressed in the endometrium during the estrous cycle and pregnancy and in the placenta [15-18]. However, the expression of LIF and LIFR in the endometrium throughout all stages of the estrous cycle and pregnancy has not been determined.

The expression of $L I F$ is increased by leptin, IL- $1 \beta$, tumor necrosis factor- $\alpha$, and transforming growth factor- $\beta$ in endometrial tissues, cultured endometrial cells, and decidua in humans [1]. In mice, endometrial expression of Lif is induced by a nidatory surge of estrogen at implantation $[10,19]$. In golden hamsters, Lif expression is induced by estrogen while the expression of Lifr and Gp130 is induced by progesterone [20]. In pigs, the expression of GP130 is not affected by estrogen and progesterone [18]. However, the regulatory mechanism of LIF and LIFR expression in the endometrium is not fully understood in pigs. Therefore, to clarify the role of LIF in the endometrium during the estrous cycle and pregnancy in pigs, we examined the temporal and cell type-specific expression of LIF and LIFR in the endometrium throughout the estrous cycle and pregnancy and the regulation of LIF and LIFR by steroid hormones, estrogen and progesterone, in endometrial tissues.

\section{MATERIALS AND METHODS}

\section{Animals and tissue preparation}

All experimental procedures involving animals were conducted in accordance with the Guide for Care and Use of Research Animals in Teaching and Research and approved by the Institutional Animal Care and Use Committee of Yonsei University and the National Institute of Animal Science. Sexually mature crossbred female gilts were assigned randomly to either cyclic or pregnant status. The reproductive tracts of gilts were obtained immediately after slaughter at a local slaughterhouse on either days $0,3,6,9,12,15$, or 18 of the estrous cycle or days $12,15,30,60,90$, or 114 of pregnancy ( $n=3-6 / d /$ status). Pregnancy was confirmed by the presence of apparently normal filamentous conceptuses in uterine flushings on days 12 and 15 and the presence of embryos and placenta on later days of pregnancy. Conceptus tissues were obtained from uterine flushings on days 12 and 15 of pregnancy, and chorioallantoic tissues were obtained on days $30,60,90$, and 114 of pregnancy $(\mathrm{n}=3-4 / \mathrm{d})$.

Endometrium, dissected free of the myometrium, was collected from the middle portion of each uterine horn, snapfrozen in liquid nitrogen, and stored at $-80^{\circ} \mathrm{C}$ prior to RNA extraction. For in situ hybridization, cross-sections of endometrium were fixed in $4 \%$ paraformaldehyde in phosphatebuffered saline (PBS) (pH 7.4) for $24 \mathrm{~h}$ and then embedded in paraffin as previously described [21]. For endometrial explant tissue cultures, endometrial tissues were obtained from sexually immature crossbred female gilts $(\mathrm{n}=8)$ with no evidence of ovulation at a local slaughterhouse immediately after pigs were slaughtered.

\section{Total RNA extraction and reverse transcription} polymerase chain reaction for LIF and LIFR cDNAs

Total RNA was extracted from endometrial, chorioallantoic, and conceptus tissues using TRIzol reagent (Invitrogen, Carlsbad, CA, USA) according to the manufacturer's recommendations. The quantity of RNA was assessed spectrophotometrically, and the integrity of RNA was validated following electrophoresis in $1 \%$ agarose gel.

Four micrograms of total RNA from endometrial, chorioallantoic, and conceptus tissues were treated with DNase I (Promega, Madison, WI, USA) and reverse transcribed using SuperScript II Reverse Transcriptase (Invitrogen, USA) to obtain cDNAs. The cDNA templates were then diluted 1:4 with nuclease-free water and amplified by polymerase chain reaction (PCR) using Taq polymerase (Takara Bio, Shiga, Japan). The PCR conditions, sequences of primer pairs for $L I F$ and LIFR, and expected product sizes are listed in Table 1. The PCR products were separated on $2 \%$ agarose gel and visualized by ethidium bromide staining. The identity of each amplified PCR product was verified by sequence analysis after cloning into the pCRII vector (Invitrogen, USA).

\section{Quantitative real-time reverse transcription polymerase chain reaction}

To analyze levels of LIF and LIFR mRNAs in endometrial and chorioallantoic tissues, real-time reverse transcription (RT)PCR was performed using the SYBR Green method with the Applied Biosystems StepOnePlus System (Applied Biosystems, Foster City, CA, USA). Complementary DNAs were synthesized from $4 \mu \mathrm{g}$ total RNA isolated from different uterine endometrial tissues, and newly synthesized cDNAs (total volume of $21 \mu \mathrm{L}$ ) were diluted 1:4 with nuclease-free water and then used for PCR. Power SYBR Green PCR Master Mix (Applied Biosystems, USA) was used for PCR reactions. The final reaction volume of $20 \mu \mathrm{L}$ included $2 \mu \mathrm{L}$ of cDNA, $10 \mu \mathrm{L}$ of $2 \mathrm{X}$ Master mix, $2 \mu \mathrm{L}$ of each primer $(100 \mathrm{nM})$, and $4 \mu \mathrm{L}$ of 
Table 1. Summary of primer sequences for reverse transcription polymerase chain reaction (RT-PCR) and real-time RT-PCR and expected product sizes

\begin{tabular}{|c|c|c|c|c|}
\hline Primer & $\begin{array}{l}\text { Sequence of forward }(F) \text { and } \\
\text { reverse }(R) \text { primers }\left(5^{\prime} \rightarrow 3^{\prime}\right)\end{array}$ & $\begin{array}{c}\text { Annealing } \\
\text { temperature }\left({ }^{\circ} \mathrm{C}\right)\end{array}$ & $\begin{array}{l}\text { Product size } \\
\text { (bp) }\end{array}$ & GenBank accession no. \\
\hline \multicolumn{5}{|c|}{ For RT-PCR and real-time PCR } \\
\hline \multirow[t]{2}{*}{ LIF } & F: TCA ATC CTG GTG CTG TGA AC & 60 & 178 & NM_214402.2 \\
\hline & R: CAG CCC AGC TTC TTC TTC TG & & & \\
\hline \multirow[t]{2}{*}{ LIFR } & F: GGT CGC AAA GAG TGG AGT GA & 60 & 163 & XM_021076925.1 \\
\hline & R:TTC TGC CAA TCT GTG CCG AT & & & \\
\hline \multicolumn{5}{|c|}{ For in situ hybridization } \\
\hline \multirow[t]{2}{*}{ LIF } & F: GTC ACC CAT GTC ACA GCA AC & 60 & 445 & NM_214402.2 \\
\hline & R: CAG CCC AGC TTC TTC TTC TG & & & \\
\hline \multirow[t]{2}{*}{ LIFR } & F:TCC CGA CAA TTT TTG ATT CC & 60 & 195 & XM_021076924.1 \\
\hline & R: TCA CAG GAT CCC TCC AAG AC & & & \\
\hline
\end{tabular}

LIF, leukemia inhibitory factor; LIFR, leukemia inhibitory factor receptor; RPL7, ribosomal protein L7.

$\mathrm{dH}_{2} \mathrm{O}$. PCR conditions and sequences of primer pairs used for LIF and LIFR are listed in Table 1. The results are reported as expression relative to the level detected on day 0 of the estrous cycle after normalization of the transcript amount to the endogenous porcine ribosomal protein L 7 (RPL7) control by the $2^{-\Delta \Delta C T}$ method [22].

\section{Non-radioactive in situ hybridization}

We performed non-radioactive in situ hybridization as previously described $[23,24]$ with minor modifications. Sections (5 $\mu \mathrm{m}$ thick) were rehydrated through successive baths of xylene, 100\% ethanol, 95\% ethanol, diethylpyrocarbonate (DEPC)-treated water, and DEPC-treated PBS. Tissue sections were boiled in citrate buffer ( $\mathrm{pH}$ 6.0) for $10 \mathrm{~min}$. After washing in DEPC-treated PBS, sections were digested using $5 \mu \mathrm{g} / \mathrm{mL}$ Proteinase K (Sigma, St. Louis, MO, USA) in TE (100 $\mathrm{mM}$ Tris- $\mathrm{HCl}, 50 \mathrm{mM}$ ethylenediaminetetraacetic acid, $\mathrm{pH}$ 7.5 ) at $37^{\circ} \mathrm{C}$. After post-fixation in $4 \%$ paraformaldehyde, sections were incubated twice for $15 \mathrm{~min}$ each in PBS containing $0.1 \%$ active DEPC and equilibrated for $15 \mathrm{~min}$ in $5 \times$ saline sodium citrate (SSC). The sections were prehybridized for $2 \mathrm{~h}$ at $68^{\circ} \mathrm{C}$ in hybridization mix ( $50 \%$ formamide, $5 \times$ SSC, 500 $\mu \mathrm{g} / \mathrm{mL}$ herring sperm DNA, $250 \mu \mathrm{g} / \mathrm{mL}$ yeast tRNA; $200 \mu \mathrm{L}$ on each section). Sense and antisense LIF and LIFR riboprobes were generated using partial cDNAs cloned into pCRII vectors by linearizing with appropriate restriction enzymes and labeling with digoxigenin (DIG)-UTP using a DIG RNA Labeling kit (Roche, Indianapolis, IN, USA). The probes were denatured for $5 \mathrm{~min}$ at $80^{\circ} \mathrm{C}$ and added to the hybridization mix. The hybridization reaction was carried out at $68^{\circ} \mathrm{C}$ overnight. Prehybridization and hybridization reactions were performed in a box saturated with a $5 \times$ SSC-50\% formamide solution to avoid evaporation, and no coverslips were used. After hybridization, sections were washed for $30 \mathrm{~min}$ in $2 \times$ SSC at room temperature, $1 \mathrm{~h}$ in $2 \times \mathrm{SSC}$ at $65^{\circ} \mathrm{C}$, and $1 \mathrm{~h}$ in
$0.1 \times \mathrm{SSC}$ at $65^{\circ} \mathrm{C}$. Probes bound to the section were detected immunologically using sheep anti-DIG Fab fragments covalently coupled to alkaline phosphatase and nitroblue tetrazolium chloride/5-bromo-4-chloro-3-indolyl phosphate (toluidine salt) as chromogenic substrate, according to the manufacturer's protocol (Roche, USA).

\section{Explant cultures}

Endometrial tissues from immature gilts were dissected from the myometrium and placed into warm phenol red-free Dulbecco's modified Eagle's medium/F-12 (DMEM/F-12) culture medium (Sigma, USA) containing penicillin G (100 IU/mL) and streptomycin $(0.1 \mathrm{mg} / \mathrm{mL})$ as described previously [21] with some modifications. The endometrium was minced with scalpel blades into small pieces ( 2 to $3 \mathrm{~mm}^{3}$ ), and aliquots of $500 \mathrm{mg}$ were placed into T25 flasks with serum-free modified DMEM/F-12 containing $10 \mu \mathrm{g} / \mathrm{mL}$ insulin (Sigma, USA), $10 \mathrm{ng} / \mathrm{mL}$ transferrin (Sigma, USA), and $10 \mathrm{ng} / \mathrm{mL}$ hydrocortisone (Sigma, USA). Endometrial explants were cultured immediately after mincing in the presence of increasing doses of estradiol- $17 \beta\left(\mathrm{E}_{2} ; 0,5,50,500\right.$, or $5,000 \mathrm{pg} / \mathrm{mL}$; Sigma, USA) and progesterone $\left(\mathrm{P}_{4} ; 0,0.3,3,30\right.$, or $300 \mathrm{ng} / \mathrm{mL}$; Sigma, USA) for $24 \mathrm{~h}$ with rocking in an atmosphere of $5 \% \mathrm{CO}_{2}$ in air at $37^{\circ} \mathrm{C}$. Explant tissues were then harvested and total RNA was extracted for real-time RT-PCR analysis to determine the effects of $\mathrm{E}_{2}$ and $\mathrm{P}_{4}$ on expression of LIF and LIFR mRNAs. These experiments were conducted using endometrial tissues from eight immature gilts.

\section{Statistical analysis}

Data from real-time RT-PCR for LIF and LIFR expression during the estrous cycle and pregnancy were subjected to analysis of variance using the general linear models procedures of SAS (Cary, NC, USA). As sources of variation, the model included day, pregnancy status (cyclic or pregnant, days 
12 and 15 post-estrus), and their interactions to evaluate steadystate levels of LIF and LIFR mRNAs, and effects of treatment and animal to evaluate effects of steroid hormones on LIF and LIFR mRNAs. Effects of day of the estrous cycle (day 0, 3, 6, $9,12,15$, and 18) and pregnancy (day 12, 15, 30, 60, 90, and 114 ) in the endometrium, effects of day of pregnancy in chorioallantoic tissue (day 30, 60, 90, and 114), and effects of dose in explant culture for data from real-time RT-PCR for LIF and LIFR expression were analyzed by least squares regression analysis. Data are presented as means with standard error of the mean. A p-values less than 0.05 were considered significant.

\section{RESULTS}

Expression of LIF and LIFR mRNAs in the endometrium during the estrous cycle and pregnancy in pigs

We performed real-time RT-PCR analysis to determine whether LIF and LIFR mRNAs were expressed in the endometrium in pigs. As shown in Figure 1, real-time RT-PCR analysis showed that the expression of LIF in the endometrium increased at late diestrus and proestrus phases during the estrous cycle (linear effect of day, $\mathrm{p}<0.05$ ), while the expression of LIFR did not change during the cycle. On days 12 and 15 post-estrus, $L I F$ expression was affected by day $(\mathrm{p}<0.05)$, but not by pregnancy status and day $\times$ status, and LIFR expression was affected by pregnancy status $(\mathrm{p}<0.05)$ and day $\times$ status $(\mathrm{p}<0.05)$, but not by day. The expression of LIFR mRNA was greater on day 15 of pregnancy than day 15 of the estrous cycle ( $<<0.05)$. During pregnancy, the expression of LIF increased towards term pregnancy with the greatest expression on day 90 of pregnancy (linear effect of day, $\mathrm{p}<0.01$ ), and whereas the expression of LIFR was greatest on day 15 and decreased thereafter (linear effect of day, $\mathrm{p}<0.01)$.

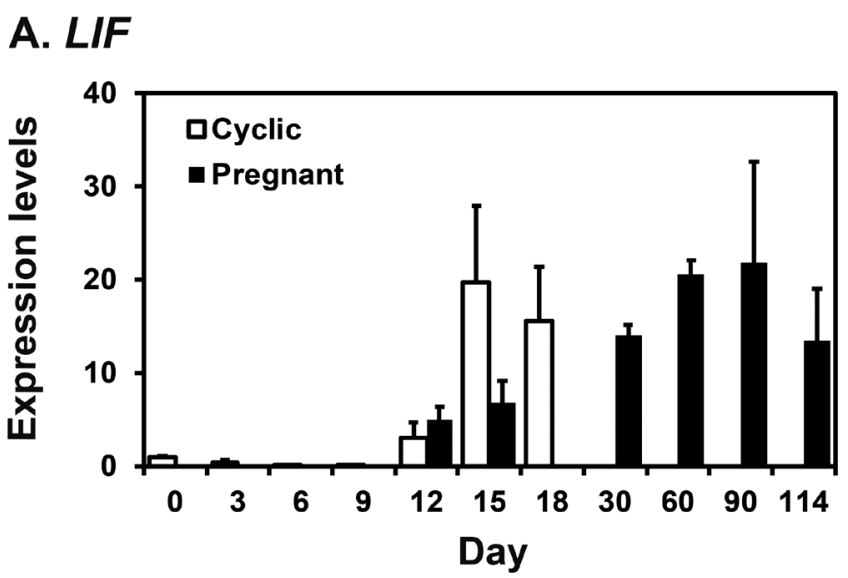

Expression of LIF and LIFR mRNA in conceptuses during early pregnancy and chorioallantoic tissue during later stage of pregnancy

We performed RT-PCR using cDNA from conceptuses from days 12 and 15 to determine whether conceptuses express $L I F$ and LIFR during early pregnancy. LIF and LIFR mRNAs were detected in conceptus tissues on both days of pregnancy (Figure 2A). We performed real-time RT-PCR analysis to determine if the expression of LIF and LIFR mRNAs changed in chorioallantoic tissues during mid- to late pregnancy. The expression of LIF mRNA increased toward term pregnancy (linear effect of day, $\mathrm{p}<0.01$ ), whereas the expression of LIFR mRNA decreased after day 30 and remained low until term (linear effect of day, $\mathrm{p}<0.05$ ) (Figure 2B).

Localization of LIF and LIFR mRNAs in the endometrium during the estrous cycle and pregnancy in pigs

Next, we performed in situ hybridization analysis to determine which cell type(s) express LIF and LIFR mRNAs in the endometrium. The expression of LIF mRNA was mainly localized to endometrial luminal and glandular epithelial cells during the estrous cycle and pregnancy and to the chorioallantoic membrane during mid- to late pregnancy. LIFR mRNA was localized primarily to endometrial epithelial cells and stromal cells during the estrous cycle and pregnancy, with strong signal intensity in stromal cells on day 15 of pregnancy (Figure 3).

Effects of $\mathrm{E}_{2}$ and $\mathrm{P}_{4}$ on LIF and LIFR mRNA expression in the endometrium

Because LIF mRNAs increased significantly at late diestrus and proestrus phases in this study and the expression of Lif and Lifr is induced by the steroid hormones estrogen and progesterone in rodent endometrium [19,20], we determined whether $\mathrm{E}_{2}$ and $\mathrm{P}_{4}$ affected the expression of LIF and LIFR

\section{B. LIFR}

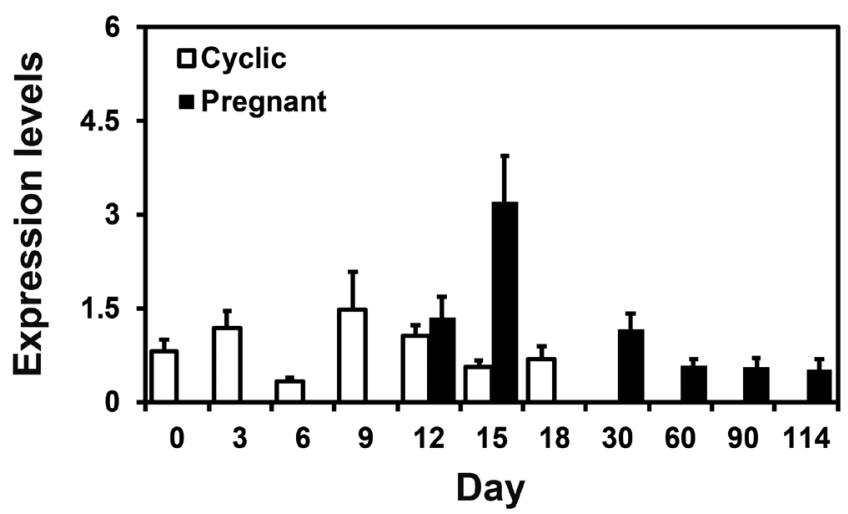

Figure 1. Expression of leukemia inhibitory factor (LIF; A) and leukemia inhibitory factor receptor (LIFR; B) mRNAs in the endometrium during the estrous cycle and pregnancy in pigs. Endometrial tissue samples from cyclic and pregnant gilts were analyzed by real-time reverse transcription polymerase chain reaction, and data are reported as expression relative to that detected on day 12 of the estrous cycle after normalization of the transcript amount to the endogenous ribosomal protein L7 control. Data are presented as means with standard errors. 
A.

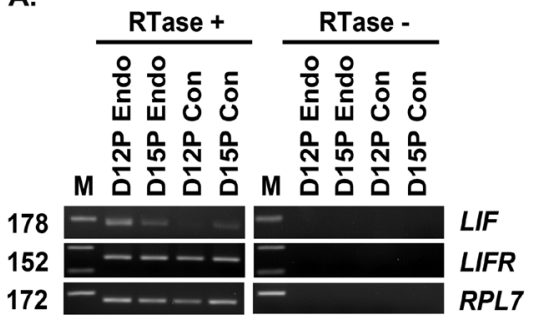

B.

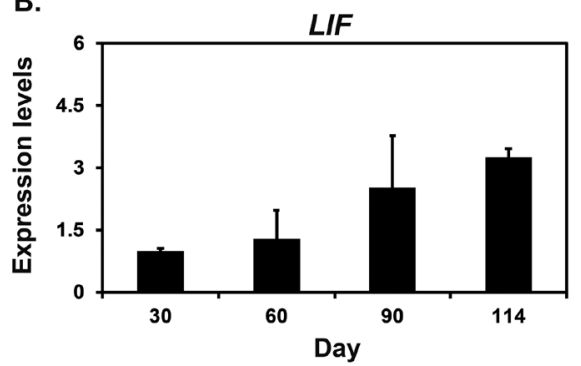

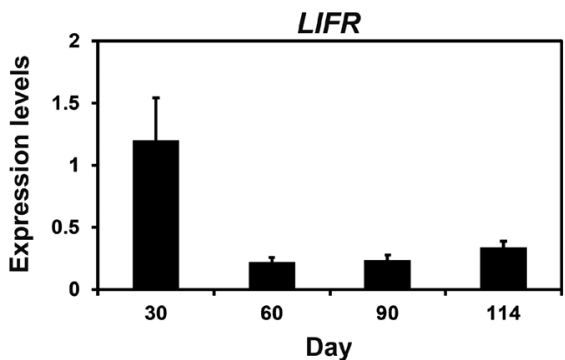

Figure 2. Analysis of leukemia inhibitory factor (LIF) and leukemia inhibitory factor receptor (LIFR) expression in conceptuses from day 12 and day 15 of pregnancy and chorioallantoic tissues during later stages of pregnancy. (A) Reverse transcription polymerase chain reaction (RT-PCR) analysis of LIF and LIFR mRNA in conceptuses on days 12 and 15 of pregnancy was performed using total RNA preparations. Ribosomal protein L7 (RPL7) was used as a positive control. RTase $+/-$, with (+) or without (-) reverse transcriptase; M, molecular marker; D12 Endo, endometrium on day 12 of pregnancy; D12 Con, day 12 conceptus; D15 Con, day 15 conceptus. (B) Real-time RTPCR analysis of the expression of LIF and LIFR mRNAs in chorioallantoic tissues on days 30, 60, 90, and 114 of pregnancy. Data are reported as expression relative to that detected on day 30 of pregnancy after normalization of the transcript amount to the endogenous RPL7 control, and data are presented as means with standard errors.

mRNAs in endometrial explant cultures from immature gilts, that were not exposed to cyclical ovarian hormones. We treated endometrial explant tissues with $0,5,50,500$, or $5,000 \mathrm{pg} / \mathrm{mL}$ $\mathrm{E}_{2}$, and found that the expression of $L I F$, but not LIFR, was
A. LIF

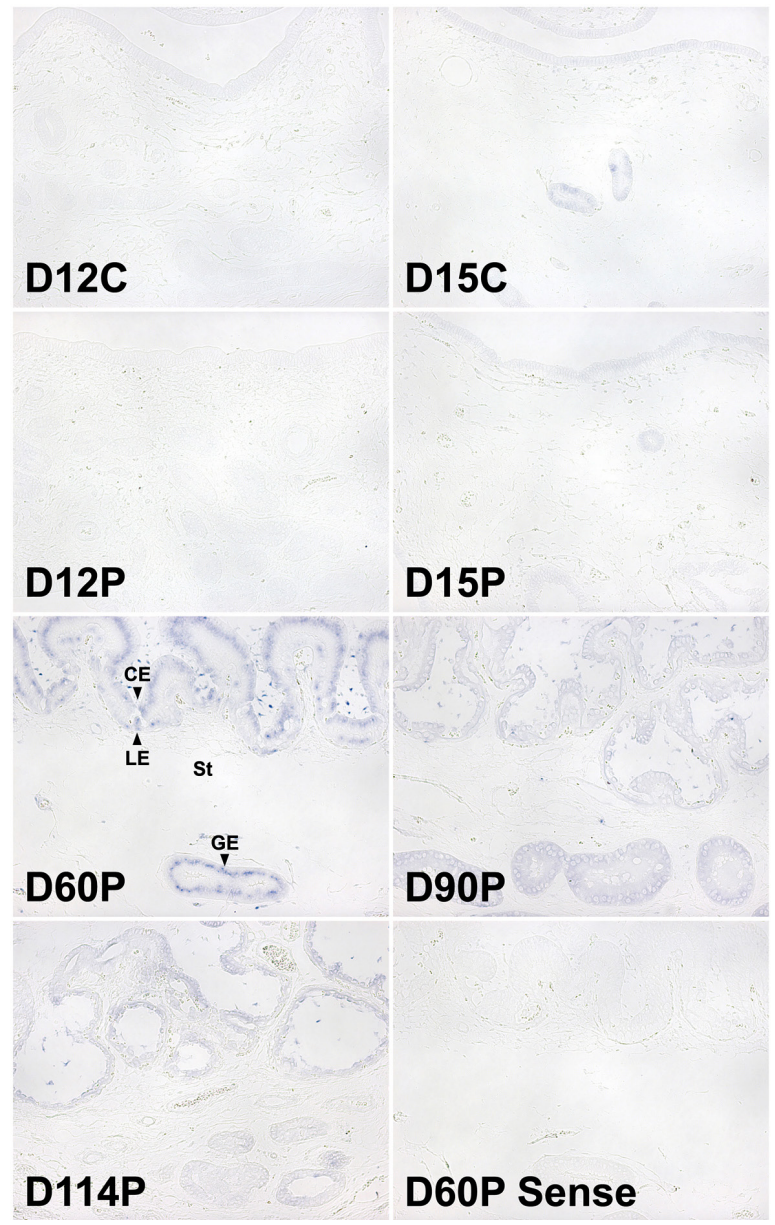

B. LIFR

D12C

D15C

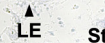

GE

D12P

D15P

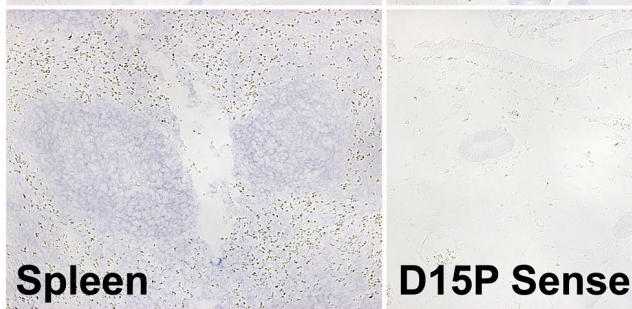

Figure 3. In situ hybridization analysis of leukemia inhibitory factor (LIF;A) and leukemia inhibitory factor receptor (LIFR; B) mRNAs in the uterine endometrium during the estrous cycle and pregnancy in pigs. Representative uterine sections from day 60 and day 15 of pregnancy, hybridized with a digoxigenin-labeled sense LIF and LIFR CRNA probe (Sense), respectively, as a negative control are shown. D, day; C, estrous cycle; P, pregnancy; LE, luminal epithelium; GE, glandular epithelium; St, stroma; CE, chorionic epithelia. Bars $=100 \mu \mathrm{m}$. 
increased by increasing doses of $\mathrm{E}_{2}$ (linear effect of dose, $\mathrm{p}<$ 0.01) (Figure 4). Furthermore, we treated endometrial explant tissues with $0,0.3,3,30$, or $300 \mathrm{ng} / \mathrm{mL} \mathrm{P}_{4}$ and found that increasing doses of $\mathrm{P}_{4}$ induced the expression of LIFR mRNA (linear effect of dose, $\mathrm{p}<0.01$ ), but not LIF mRNA (Figure 5).

\section{DISCUSSION}

The novel findings of this study in pigs are as follows: i) LIF and LIFR mRNAs are expressed in the endometrium throughout the estrous cycle and pregnancy in a stage-specific manner; ii) conceptus tissues on days 12 and 15 and chorioallantoic tissues from day 30 to term express LIF and LIFR mRNAs; iii) LIF and LIFR mRNAs are localized to epithelial and stromal cells in the endometrium; and iv) the expression of LIF in the endometrium is increased by $\mathrm{E}_{2}$, while LIFR is increased by $\mathrm{P}_{4}$. To our knowledge, this is the first report to determine the expression of LIF and LIFR throughout the estrous cycle and pregnancy in pigs.

LIF and LIFR are expressed in the endometrium, and their expression changes depending on the stage of the reproductive cycle and pregnancy, in humans and rodents. In human endometrium, LIF expression increases during the secretory phase of the menstrual cycle $[7,8]$, and LIFR and GP130 are expressed in epithelial cells during the cycle [8]. In mice, Lif expression in the endometrium is greatest on day 4 during pregnancy, which coincides with the onset of blastocyst implantation, and remains low after implantation [10]. In the
A. LIF

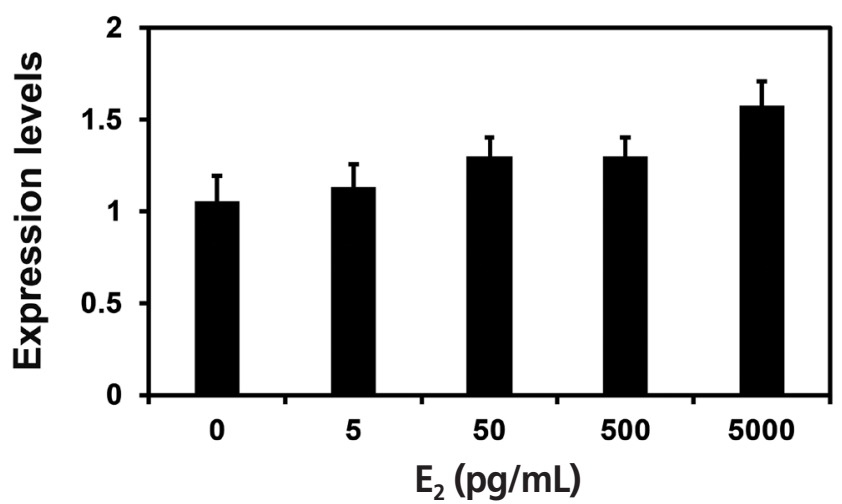

B. LIFR

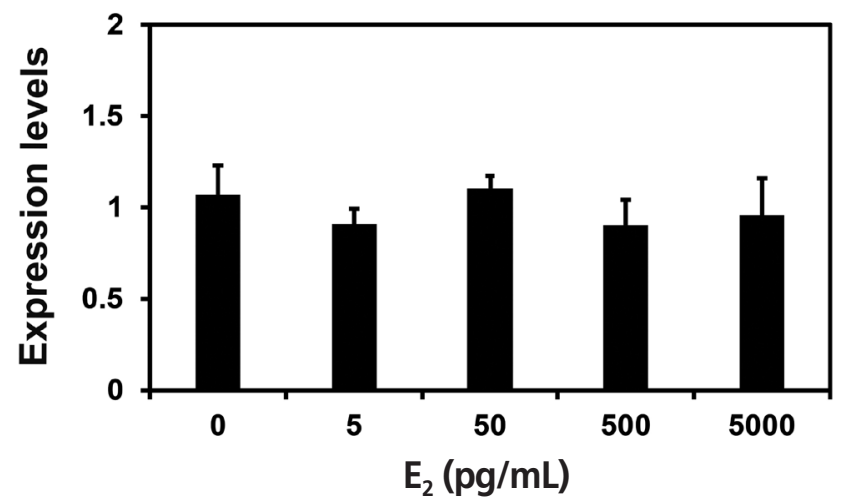

Figure 4. Effects of $E_{2}$ on leukemia inhibitory factor (LIF) and leukemia inhibitory factor receptor (LIFR) mRNA levels in endometrial explant cultures. Endometrial explants from immature gilts were cultured in the presence of increasing doses of $E_{2}(0,5,50,500$, or $5,000 \mathrm{pg} / \mathrm{mL})$ at $37^{\circ} \mathrm{C}$ for $24 \mathrm{~h}$. For each treatment, experiments were performed with endometria from eight gilts. Abundance of mRNA expression determined by real-time reverse transcription polymerase chain reaction analyses is relative to that for LIF and LIFR mRNAs in the control group of endometrial explants $(0 \mathrm{pg} / \mathrm{mL})$ after normalization of transcript amounts to ribosomal protein $\mathrm{L} 7 \mathrm{mRNA}$. Data are presented as least squares means with standard errors.
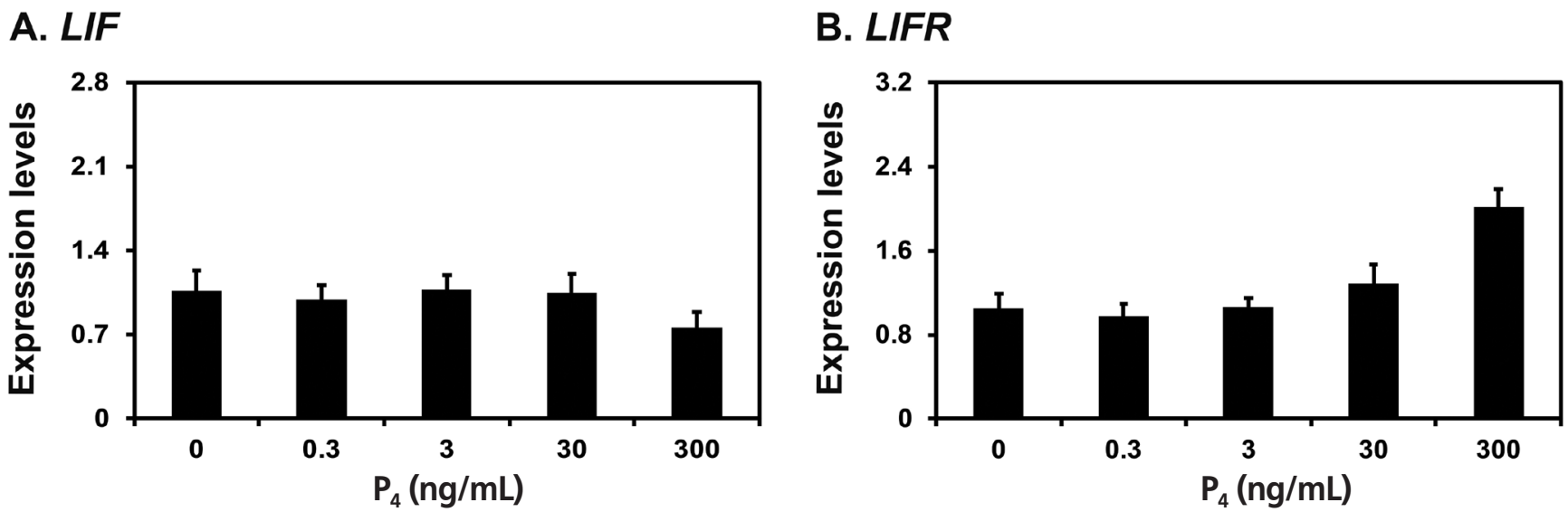

Figure 5. Effects of $\mathrm{P}_{4}$ on leukemia inhibitory factor (LIF) and leukemia inhibitory factor receptor (LIFR) mRNA levels in endometrial explant cultures. Endometrial explants from immature gilts were cultured in the presence of increasing doses of $\mathrm{P}_{4}(0,0.3,3,30$, or $300 \mathrm{ng} / \mathrm{mL})$ at $37^{\circ} \mathrm{C}$ for $24 \mathrm{~h}$. For each treatment, experiments were performed with endometria from eight gilts. Abundance of mRNA expression determined by real-time RT-PCR analyses is relative to that for LIF and LIFR mRNAs in the control group of endometrial explants $(0 \mathrm{pg} / \mathrm{mL})$ after normalization of transcript amounts to ribosomal protein $\mathrm{L} 7 \mathrm{mRNA}$. Data are presented as least squares means with standard errors. 
present study, we found that LIF was expressed in the endometrium throughout the estrous cycle and pregnancy in pigs. During the estrous cycle, LIF expression was greatest at late diestrus and proestrus phases. These phases correspond to the period of luteolysis and follicular development, which, in turn, causes decline of progesterone and increase of estrogen. Because endometrial prostaglandin $(\mathrm{PG}) \mathrm{F}_{2 \alpha}$ production is critical for the induction of luteolysis [25], we hypothesize that LIF is involved in endometrial function for the production of luteolytic PGs. In addition, because the proportion of macrophages in the endometrium significantly decreases at the time of implantation in Lif-null mice [26] and immune cell recruitment into the endometrium increases during the proestrus phase after luteolysis in pigs [27], LIF may be involved in regulation of immune cell recruitment into the endometrium during the estrous cycle.

LIF plays a critical role in implantation and decidualization in the uterus to increase receptivity to the developing embryo during early pregnancy in humans and rodents [1]. In pigs, the expression of LIF in the endometrium during pregnancy was greatest during mid- to late stages of pregnancy. Because LIF increases cell attachment and viability of porcine trophoblast cells in vitro [14] and was most expressed during midto late pregnancy, it is likely that LIF plays an important role in placental development and cell adhesion between the trophoblast and endometrial epithelial cells during mid- to late stages of pregnancy. The endometrial expression of GP130, which forms a heterodimeric LIF receptor with LIFR, also increases during mid-pregnancy with the greatest expression on day 60 of pregnancy in pigs [18]. Based on the expression pattern of endometrial LIF during pregnancy, it is likely that the function of LIF for conceptus implantation in pigs is not as critical as in humans and rodents. This may be due to differences in implantation and placentation in pigs, which forms a non-invasive true epitheliochorial type placenta and does not require a decidualization process during the implantation period, whereas in humans and rodents the endometrium is decidualized for implantation and an invasive hemochorial type placenta is formed when the embryo is implanted.

The expression of LIFR in the endometrium has been shown in humans [7,8], rodents [20], and pigs [16,17], but the temporal pattern of LIFR expression throughout the menstrual or estrous cycle and pregnancy has not been studied in any species so far. In this study, we found that the expression of LIFR in the endometrium was constitutive throughout the estrous cycle in pigs, but changed during pregnancy with the greatest abundance on day 15 . These findings suggest that LIFR and GP130 are both expressed in the endometrium, but their endometrial expression during pregnancy is differentially regulated in pigs.

Porcine conceptus tissues expressed LIF and LIFR during early pregnancy, and chorioallantoic tissues also expressed
LIF and LIFR during mid- to late pregnancy. These data coincide with previous reports that LIF and LIFR are expressed in the conceptus and fetal membrane tissues $[14,15]$. We further determined that LIF expression in chorioallantoic tissues increased towards term pregnancy in pigs, while LIFR expression decreased, suggesting a role of LIF in placental function. Based on localization of LIF and LIFR in the endometrium and conceptus tissues, it is likely that LIF acts on endometrial epithelial cells and conceptus/chorioallantoic tissues in an autocrine and/or paracrine manner to affect endometrial and conceptus function during pregnancy in pigs.

$L I F$ is expressed in endometrial epithelial cells during the menstrual cycle and endometrial epithelial cells, decidual cells, and decidual leukocytes during early pregnancy in humans $[8,28]$. LIFR is expressed in only endometrial luminal and glandular epithelial cells during the cycle, whereas it is expressed in endometrial epithelial cells, endothelial cells, and villous and extravillous trophoblasts during pregnancy in humans [8,28]. In this study, LIF expression was detected primarily in endometrial epithelial cells during the estrous cycle and pregnancy and in chorioallantoic membrane during mid- to late pregnancy in pigs. LIFR expression was also detected in endometrial epithelial cells in the endometrium, and endometrial stromal cells expressed LIFR at increased levels on day 15 of pregnancy, which is the time when many immune cells such as T cells and NK cells are recruited into the endometrium during pregnancy in pigs [29]. These data suggest that LIF and LIFR act on endometrial epithelial cells in an autocrine manner and on stromal cells in a paracrine manner.

The expression of LIF is increased by cytokines, leptin, and estrogen in endometrial cells in humans and rodents $[1,10,19]$, and the expression of Lifr is induced by $\mathrm{P}_{4}$, but not by $\mathrm{E}_{2}$, in the endometrium of golden hamsters [20]. Based on the patterns of LIF and LIFR expression in the endometrium during the estrous cycle and pregnancy observed in this study and reports in other species $[1,10,19,20]$, we hypothesized that ovarian steroid hormones affect the expression of LIF and LIFR in the porcine endometrium. Indeed, our results in this study indicate that estrogen increased the expression of LIF and progesterone increased the expression of LIFR in endometrial tissues. These data suggest that estrogen and progesterone play critical roles in regulating the expression of LIF and LIFR in the endometrium during the estrous cycle and pregnancy, and that the regulation of endometrial LIF and LIFR expression by steroid hormones is similar among species. In mice, the expression of Lif dramatically increases in the endometrium at the time of implantation, and estrogen is responsible for the increase of endometrial Lif expression [10,19]. In pigs, conceptus implantation initiates on day 12 of pregnancy and the implanting conceptus produces estrogen, which acts as a maternal pregnancy recognition signal [25]. Thus, we postulated that endometrial expression of LIF increased in response 
to conceptus-derived estrogen in pigs. However, our results showed that LIF expression was not different between day 12 of the estrous cycle and pregnancy. This suggests that conceptus-derived estrogen may not be responsible for endometrial expression of LIF in pigs, and that the regulatory mechanism underlying endometrial LIF expression is different between rodents and pigs because of differences in implantation and placentation.

We also found that the endometrial expression of LIFR was greatest on day 15 of pregnancy, when the implanting conceptus produces the large amounts of cytokines such as interferons (IFNs), IFN- $\gamma$, and IFN- $\delta$ [25], and the endometrium produces cytokines and chemokines such as cysteine-X-cysteine motif chemokine ligand (CXCL) 9, CXCL10, and CXCL11 [29]. Thus, it is possible that these cytokines derived from the conceptus and the endometrium affect the expression of endometrial LIFR at the time of implantation in pigs, but further study of the factors regulating endometrial LIFR expression on day 15 of pregnancy are necessary to elucidate this hypothesis.

In conclusion, in this study we showed that LIF and LIFR are expressed in the endometrium in a stage-specific manner during the estrous cycle and pregnancy and in conceptus and chorioallantoic tissues during pregnancy in pigs. Estrogen and progesterone regulate the expression of LIF and LIFR in the endometrium, respectively. Although the role of LIF in the endometrium during the estrous cycle and pregnancy is not fully understood, our results indicate that LIF and its receptor signaling system play important roles in regulating endometrial function during the estrous cycle and at the maternalconceptus interface during mid- to late-pregnancy in pigs.

\section{CONFLICT OF INTEREST}

We certify that there is no conflict of interest with any financial organization regarding the material discussed in the manuscript.

\section{ACKNOWLEDGMENTS}

This study was supported by the Next Generation BioGreen 21 Program (\#PJ01110301; \#PJ01119103), Rural Development Administration, and by the Korea Research Foundation (\#2015 R1D1A1A01058356), Republic of Korea.

\section{REFERENCES}

1. Kimber SJ. Leukaemia inhibitory factor in implantation and uterine biology. Reproduction 2005;130:131-45.

2. Rosario GX, Stewart CL. The multifaceted actions of leukaemia inhibitory factor in mediating uterine receptivity and embryo implantation. Am J Reprod Immunol 2016;75:246-
55.

3. Nicola NA, Babon JJ. Leukemia inhibitory factor (LIF). Cytokine Growth Factor Rev 2015;26:533-44.

4. Boeuf H, Hauss C, Graeve FD, Baran N, Kedinger C. Leukemia inhibitory factor-dependent transcriptional activation in embryonic stem cells. J Cell Biol 1997;138:1207-17.

5. Williams RL, Hilton DJ, Pease S, et al. Myeloid leukaemia inhibitory factor maintains the developmental potential of embryonic stem cells. Nature 1988;336:684-7.

6. Salleh N, Giribabu N. Leukemia inhibitory factor: roles in embryo implantation and in nonhormonal contraception. Sci World J 2014;2014:Article ID 201514.

7. Charnock-Jones DS, Sharkey AM, Fenwick P, Smith SK. Leukaemia inhibitory factor mRNA concentration peaks in human endometrium at the time of implantation and the blastocyst contains mRNA for the receptor at this time. J Reprod Fertil 1994;101:421-6.

8. Cullinan EB, Abbondanzo SJ, Anderson PS, et al. Leukemia inhibitory factor (LIF) and LIF receptor expression in human endometrium suggests a potential autocrine/paracrine function in regulating embryo implantation. Proc Natl Acad Sci USA 1996;93:3115-20.

9. Shuya LL, Menkhorst EM, Yap J, et al. Leukemia inhibitory factor enhances endometrial stromal cell decidualization in humans and mice. PLoS One 2011;6:e25288.

10. Bhatt H, Brunet LJ, Stewart CL. Uterine expression of leukemia inhibitory factor coincides with the onset of blastocyst implantation. Proc Natl Acad Sci USA 1991;88:11408-12.

11. Cheng JG, Chen JR, Hernandez L, Alvord WG, Stewart CL. Dual control of LIF expression and LIF receptor function regulate Stat3 activation at the onset of uterine receptivity and embryo implantation. Proc Natl Acad Sci USA 2001;98:86805.

12. Stewart CL, Kaspar P, Brunet LJ, et al. Blastocyst implantation depends on maternal expression of leukaemia inhibitory factor. Nature 1992;359:76-9.

13. Blitek A, Kaczmarek MM, Kiewisz J, Ziecik AJ. Endometrial and conceptus expression of HoxA10, transforming growth factor beta1, leukemia inhibitory factor, and prostaglandin $\mathrm{H}$ synthase-2 in early pregnant pigs with gonadotropin-induced estrus. Domest Anim Endocrinol 2010;38:222-34.

14. Blitek A, Morawska E, Ziecik AJ. Regulation of expression and role of leukemia inhibitory factor and interleukin- 6 in the uterus of early pregnant pigs. Theriogenology 2012;78:951-64.

15. Modric T, Kowalski AA, Green ML, Simmen RC, Simmen FA. Pregnancy-dependent expression of leukaemia inhibitory factor (LIF), LIF receptor-beta and interleukin-6 (IL-6) messenger ribonucleic acids in the porcine female reproductive tract. Placenta 2000;21:345-53.

16. Ostrup E, Bauersachs S, Blum H, Wolf E, Hyttel P. Differential endometrial gene expression in pregnant and nonpregnant sows. Biol Reprod 2010;83:277-85. 
17. Kaczmarek MM, Krawczynski K, Najmula J, et al. Differential expression of genes linked to the leukemia inhibitor factor signaling pathway during the estrus cycle and early pregnancy in the porcine endometrium. Reprod Biol 2014;14:293-7.

18. Yoo I, Han J, Kim M, et al. Expression and regulation of interleukin 6 and its receptor at the maternal-conceptus interface during pregnancy in pigs. Theriogenology 2017;96:85-91.

19. Chen JR, Cheng JG, Shatzer T, et al. Leukemia inhibitory factor can substitute for nidatory estrogen and is essential to inducing a receptive uterus for implantation but is not essential for subsequent embryogenesis. Endocrinology 2000;141:4365-72.

20.Ding T, Song H, Wang X, Khatua A, Paria BC. Leukemia inhibitory factor ligand-receptor signaling is important for uterine receptivity and implantation in golden hamsters (Mesocricetus auratus). Reproduction 2008;135:41-53.

21. Seo H, Kim M, Choi Y, Lee CK, Ka H. Analysis of lysophosphatidic acid (LPA) receptor and LPA-induced endometrial prostaglandin-endoperoxide synthase 2 expression in the porcine uterus. Endocrinology 2008;149:6166-75.

22.Livak KJ, Schmittgen TD. Analysis of relative gene expression data using real-time quantitative PCR and the 2(-Delta Delta $C(T))$ method. Methods 2001;25:402-8.

23. Braissant O, Wahli W. Differential expression of peroxisome proliferator-activated receptor-alpha, -beta, and -gamma during rat embryonic development. Endocrinology 1998;139:2748-54.

24.Jang H, Choi Y, Yoo I, et al. Expression and regulation of prostaglandin transporters, ATP-binding cassette, subfamily C, member 1 and 9 , and solute carrier organic anion transporter family, member $2 \mathrm{~A} 1$ and $5 \mathrm{~A} 1$ in the uterine endometrium during the estrous cycle and pregnancy in pigs. Asian-Australas J Anim Sci 2017;30:643-52.

25. Bazer FW, Johnson GA. Pig blastocyst-uterine interactions. Differentiation 2014;87:52-65.

26.Schofield G, Kimber SJ. Leukocyte subpopulations in the uteri of leukemia inhibitory factor knockout mice during early pregnancy. Biol Reprod 2005;72:872-8.

27. Kaeoket K, Donto S, Nualnoy P, Noiphinit J, Chanapiwat P. Effect of gamma-oryzanol-enriched rice bran oil on quality of cryopreserved boar semen. J Vet Med Sci 2012;74:1149-53.

28. Sharkey AM, King A, Clark DE, et al. Localization of leukemia inhibitory factor and its receptor in human placenta throughout pregnancy. Biol Reprod 1999;60:355-64.

29. Han J, Gu MJ, Yoo I, et al. Analysis of cysteine-X-cysteine motif chemokine ligands 9, 10, and 11, their receptor CXCR3, and their possible role on the recruitment of immune cells at the maternal-conceptus interface in pigs. Biol Reprod 2017;97:6980. 